\title{
Spatial Justice Models: An Exploratory Analysis on Fair Distribution of Opportunities
}

\author{
Fillipe Oliveira Feitosa ${ }^{(凶)}$ (D), Jan-Hendrik Wolf (D), and João Lourenço Marques (D) \\ Universidade de Aveiro, 3810-193 Aveiro, Portugal \\ fillipefeitosa@ua.pt
}

\begin{abstract}
Equity, fairness, and justice are related concepts widely discussed in several areas of study but remain an open field in terms of spatial justice and support decision systems application. Uneven spatial development have shown a tendency to amplify social inequalities alongside territories. To better understand the spatial configuration and spatial distribution of resources for different social groups, multiple objective criteria can be used to formulate optimal resource allocation. This work discusses spatial justice by utilitarianism and Rawlsian difference principle perspectives to formulate two models based on facility location problem (FLP) framework. Assuming the proximity to a desired opportunity (service or resource) as a measure of wellbeing and satisfaction, we weight the distances to the nearest facility by a social factor based on exponential function. Optimization results tend to favor outliers for weighted FLP, while the regular distances FLP formulation tend to favor heavy urban areas. We found that results are heavy context based, as the distribution of social groups are determinant in optimization process.
\end{abstract}

Keywords: Spatial justice $\cdot$ Social justice $\cdot$ Optimization $\cdot$ Facility location problem

\section{Introduction}

Cities can be considered the centres of modern societies. Although urbanization is an ancient phenomenon, city growth accelerated after the industrial revolution in the 19th century, when concerns regarding infrastructures such as transportation, security, and health led to public and private investments that reshaped the urban environment [1]. But resources flow unevenly into urban development. Business and private resources tend to be allocated to zones where they can generate the highest returns on revenue, considering that location is related with business success [2].

Public investments, while being committed to a certain level of equity, also tend to concentrate in more central locations. This led to a focus on spatial inequalities and their consequences to society. Recent studies have, for example, shown that territorial

This work has been supported by Portuguese national and EU funds through the Foundation for Science and Technology, FCT, I.P., in the context of the JUST_PLAN project (PTDC/GESOUT/2662/20) and the DRIVIT-UP project (POCI-01-0145-FEDER-031905) and the research unit on Governance, Competitiveness and Public Policy (UIDB/04058/2020)+(UIDP/04058/2020). 
inequalities may lead to poor accessibility to services of general interest [3], low economic potential [4], or precarious living conditions [5], which lay the foundation to demographic decline by increasing unemployment and social exclusion [6].

The way the spatial allocation of resources and services relates to this policy goal is a subject open to debate. From a business perspective, it is important to achieve an optimal allocation based on profit-maximizing goals. From a public policy perspective, justice in the distribution of spatial amenities, must also be addressed. But it is not always easy to separate these two perspectives, since, as observed by Stiglitz, politics tend to shape the market in such a way that the structure became favourable to wealthier groups at the expense of the rest [7]. While the political aspects of resource distribution are not a specific focus of this work, this argument stresses the need to consider the complex dynamics of spatial resource allocation and the, often conflicting, goals it maximizes.

Previous work in this field discussed the balance between efficiency and equity, concluding that even efficiency-focused scenarios can be considered 'fair', depending on the understanding of equity [8]. Therefore, the challenge is to define the desired goals that need to be satisfied and to translate what is a just distribution of resources into objective. From a planning perspective, the spatial distribution of services or facilities is often approached through location analysis and, namely, by solving facility location problems [9]. This kind of problem represents an established tool to determine the optimal locations for the installation of facilities to provide for existing consumer demand [10], using models that range in complexity from simple linear, uncapacitaded to nonlinear probabilistic models [11].

In this work, this modelling framework is used to analyse equity in the spatial distribution of public services, considering that there are many different definitions of spatial equity and, also, many understandings of what they mean in practice. More specifically, it aims to show how different justice principles can be incorporated in the formulation of objective functions that can be optimized to provide different spatial distributions of facilities (opportunities). This approach will be illustrated in the case of primary school locations in a peripheral municipality of Lisbon, Portugal (Loures), attributing weights to the accessibility of different socioeconomic groups and analysing the outcomes according to different indicators.

The solutions are, of course, not deterministic, in the sense that contextual problems may have distinct optimal solutions, specific restrictions, and even special conditions that cannot be optimized at all. Nonetheless, we believe that this analysis con-tributes to location analysis, providing operational insights and practical discussions of different ways to incorporate equity principles in spatial planning. The methodology and the analysis details are described in the data and methods section, following a brief review of principles of justice for location analysis. Afterwards, the results are presented and discussed. The final section includes conclusions and main findings.

\subsection{Principles of Justice for Location Analysis}

Assuming that the spatial location of services of general interest should follow principles of spatial equity does not answer the question of what these principles should be. Two major lines of reasoning can be identified in this regard. The first is a utilitarian 
perspective, where individuals are treated as equals and the benefits of resource distribution are, accordingly, weighted equally. As noted by Mandal et al., (2016), utilitarian approaches, aiming to maximize aggregate welfare, are concerned with providing the maximum benefit to the greatest number of people, disregarding the differences in individuals initial position of the inequalities that might arise from this process (for a more thorough discussion of utilitarian principles see, for example, [13]).

Regarding spatial accessibility Pereira et al. [10] consider that, from an utilitarian perspective, promoting the spatial accessibility of higher income classes at the expense of lower income classes can be justified, as long as it brings net benefits. A schematical representation of optimum locations under utilitarianism assumptions is shown in Fig. 1(left).

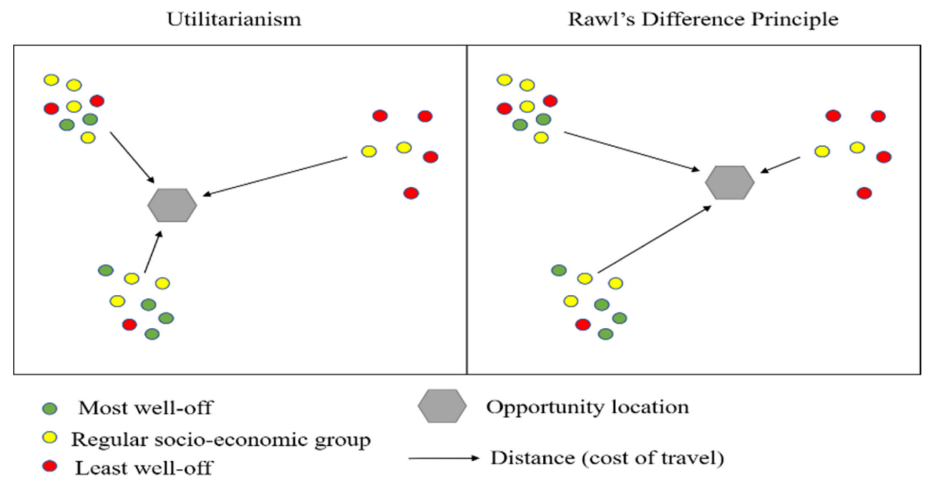

Fig. 1. Illustration of spatial justice representation of Utilitarianism (left) and Rawl's Difference Principle (right).

A different perspective can be found in authors which assume justice as the main goal which should guide public policies, such as Fainstein (2009), Sen (1992) or Rawls (1971, 1981). Rawlsian principles, in particular, are frequently evoked to justify setting limits to the inequalities generated by the spatial distribution of resources. According to Rawls, inequalities should be structured in a way that confers the most benefit to the least well-off. This definition assumes that a certain level of inequality will always exist, but that public policies should aim to redistribute resources and promote justice, to guarantee a maximum degree of freedom to different social groups and individuals, taking into consideration the different initial conditions with which they enter society.

In location analysis this principle can broadly be understood as meaning that accessibility levels should be highest for those whose initial position is worse. The solutions that best fit with this perspective are those that locate spatial amenities closest to the less privileged (see Fig. 1 right).

One major question that is not answered by this discussion is exactly who are the worse of in a given state-of-affairs. Or, in other words, which are the dimensions in which inequalities should be evaluated. Regarding spatial accessibility there are two major approaches. The first one only considers inequalities in accessibility levels. This approach is concerned with guaranteeing that no-one is above certain thresholds or 
that the spatial distribution of amenities minimizes the inequalities between different territories (examples of this approach can be found in $[18,19]$ ). The second one considers the levels of accessibility that are provided to different social groups. It has, in this regard, been noted that lower socioeconomic groups tend to have worse accessibility to spatial resources such as public parks [20] or, indeed, schools [3, 21].

This work is in line with the second approach, considering the way spatial accessibility to public facilities (opportunities) is related with pre-existing inequalities. This means it will maximize accessibility goals but weight the distances of different socio-economic groups differently. We intend to create scenarios of fairness that can be compared to the existing opportunities distribution in terms of accessibility metrics.

\section{Data and Methods}

Accessibility can be defined as the ease of reaching relevant activities, individuals, or opportunities [22], and its meaning is closed related to the spatial distribution of destinations. Our work assumes that proximity to opportunities plays an important factor in individual development and well-being. This is not a novel concept and has already been stressed by Sen [23], who argues that access to opportunities is vital for justice and individual freedom, and was revisited by the planning theory [14] regarding the justice in the spatial distribution of services.

In this work, we go a step further by addressing the "easiness" of access in accessibility. As previously argued, Ralw's Difference Principle states that inequalities may occur if they promote the least well-off, but it is not clear how the least well-off are to be identified and, if these social differences do exist, how this reflects on the access to opportunities. In other words, how hard is for the least privileged in a given context to reach their relevant destination? This subject is addressed by adjusting the distance to the nearest opportunity to a "social cost" factor and using facility location problem (FLP) as a framework to create optimal services locations to analyze how the real distribution relates to them. By doing this weighed FLP formulation, we intend to model Ralw's justice principles tending optimization to the least well-off, in contrast with the regular FLP model, that will maximize the overall welfare by satisfying the populated areas demand without taking socio-economic factor into account.

Facility location problems optimize objective functions which express different goals in the spatial distribution of resources. A detailed formulation can be found on [24], and several use cases can be found on [25]. Applications on justice principles often requires clever approaches to the objection function and its restrictions. For instance, Hooker [26] uses objectives functions to find just resource distribution from both utilitarian and distributive justice perspectives.

Here, these two perspectives are applied to analyze the accessibility to primary schools in the municipality of Loures, assessing how the attribution of different weights to different social groups affects the spatial layout of the school network. For this, we consider the student population of the 628 census tracts, which leads to a total demand of 2407 school aged children. To classify the region socio-economic situation a qualification index (QI) was formulated based on the years of schooling (Table 1), discussed in Marques et al. (2020). Three different groups were considered in this index: 
group 0 includes those with less than 6 years of schooling, group 1 those from 6 to 11 years, and group 2 those with more than 11 years.

We chose to limit the capacity of school facilities to 80 students, which is the number considered necessary for their good functioning according to Portugal national planning guidelines (DGOTDU, 2002).

The objective function (Eq. 1) will minimize the sum of the distances (or "costs") $c_{i j}$ from the location $\mathrm{i}$ to the potential opportunity $\mathrm{j}$ (in this case a primary school), times the amount of demand that is correspondent times the fraction of demand $y_{i j}$ allocated to that opportunity. The restrictions (Eq. 2) indicate that the demand of every census tract must be satisfied, respecting every capacity.

$$
\begin{gathered}
\text { minimize: } \sum_{i=1}^{n} \sum_{j=1}^{m} c_{i j} y_{i j} \\
\text { subject to: } \sum y_{i j}=d_{i} \text { for } i,=1, \ldots n \\
\sum y_{i j} \leq M_{j} x_{j}, \text { for } j=1, \ldots, m ; \text { for } i=1, \ldots, n \\
y_{i j} \leq d_{i} x_{j}, \text { for } i=1, \ldots, n ; j=1, \ldots, m \\
x_{j} \in\{0,1\} \text { for } j=1, \ldots, m
\end{gathered}
$$

All 628 census tracts are considered potential location for a school. The model ran with two configurations. The first one considered the real distances to the nearest facility (to maximize overall utility) and the second one weighted the real distance by an exponential cost function (our Rawlzian distributive justice modeling proposal), giving more weight to lower socio-economic groups (group 0) than privileged ones (groups 1 and 2). There are many different cost functions (impedance functions) which can be used for this effect. There, we chose an exponential function which, according to Vale [27] is the most frequently used in the scientific literature. While these authors tested several combinations of factors to verify their influence on accessibility, we chose to use different B for each social group (see Table 1) to create the aggregate socioeconomic difficulty to reach the destination.

Finally, we compared the results using exploratory data analysis. We considered the mean, the standard deviation, the minimum and maximum values to understand how the different models used for optimization differ from each other, and how the real distribution of opportunities relates to them. 
Table 1. Data and measures overview.

\begin{tabular}{|c|c|c|c|}
\hline Indicator/measure & Description & Initial data & Source \\
\hline $\begin{array}{l}\text { Distance to the nearest } \\
\text { opportunity (school) }\end{array}$ & $\begin{array}{l}\text { Distance calculated for } \\
\text { different nodes of the } \\
\text { urban network and then } \\
\text { matched with parishes } \\
\text { geometry by } \\
\text { intersecting them with } \\
\text { these nodes }\end{array}$ & $\begin{array}{l}\text { i) schools by } \\
\text { coordinates for the } \\
\text { council (Loures) } \\
\text { ii) Street Network }\end{array}$ & $\begin{array}{l}\text { i) DGEEC } \\
\text { ii) OpenStreetMap }\end{array}$ \\
\hline Qualification index & $\begin{array}{l}\text { The qualification index } \\
\text { is calculated for every } \\
\text { parish, based on the } \\
\text { following formula: } \\
Q I=\frac{\sum y_{i} x_{i}}{\sum y_{i}} \\
\text { Where } x \text { are the years } \\
\text { in each cycle of studies, } \\
y \text { is the number of } \\
\text { people in that cycle, } \\
\text { and } i \text { is the parish }\end{array}$ & $\begin{array}{l}\text { i) Spatially delimited } \\
\text { statistical units } \\
\text { (parishes) } \\
\text { ii) data for population } \\
\text { by educational level for } \\
\text { the Census } 2011\end{array}$ & $\begin{array}{l}\text { i) BGRI } \\
\text { ii) INE }\end{array}$ \\
\hline Cost function & $\begin{array}{l}\text { Impedance factors that } \\
\text { weight the distance to } \\
\text { reflect how hard is for a } \\
\text { social group reach a } \\
\text { relevant opportunity } \\
f\left(C_{i j}\right)=e^{\left(\beta C_{i j}\right)} \\
\text { Where } C_{i j} \text { is the cost } \\
\text { (or distance) of moving } \\
\text { from } i \text { to } j \text {, and } \beta \text { is a } \\
\text { factor that adjust the } \\
\text { function }\end{array}$ & $\begin{array}{l}\text { i) } \beta=0.007 \text { if Group } \\
0 \\
\text { ii) } \beta=0.005 \text { if Group } \\
1 \\
\text { iii) } \beta=0.003 \text { if Group } \\
2\end{array}$ & [27] \\
\hline
\end{tabular}

\section{Results}

The weight imposed by the cost function upon the distances induces gaps between the social groups. As the outliers can get quite distant from the urban center, their cost gets too high, so the model adjusts opportunities in a sparse fashion that generates high dispersion. The zero in minimum distances on Table 2 means that the one opportunity (school) got located in the exact place as the one of the group census tracts during the optimization process.

Benefited by both their proximity to the denser urban center and the middle cost factor that is still quite forgiving to the distance, group 1 was the most benefited by our cost function choice. The occupation pattern plays an important part, as this groups tend to live close to populated areas, where the difference between the weighted costs can get 
quite low, even among different social groups. This pattern can also be observed on the higher minimum lower mean distances for the weighted FLP.

Group 2 accessibility improved with weighted FLP, even if the cost does not benefit them directly. This behavior was not expected, as their cost of travel is lower and optimal opportunity location would tend to avoid being too close of this group, in favor off better accessibility for group 0 and group 1. Closer analysis reveals that occupation pattern of group 2 tends to be around denser areas, even more than group 1, in such a way that they remain close to local schools. Therefore, the group 2 accessibility metrics improvement are directly related to the occupation pattern, and probably would differ if the illustration case selected were any different.

Table 2. Accessibility metrics aggregated by social group.

\begin{tabular}{l|l|l|l|l|c}
\hline Scenarios & Group & $\begin{array}{l}\text { Minimum } \\
\text { distance }\end{array}$ & $\begin{array}{l}\text { Maximum } \\
\text { distance }\end{array}$ & Mean distance & $\begin{array}{l}\text { Standard } \\
\text { deviation }\end{array}$ \\
\hline \multirow{2}{*}{ Real scenario } & Group 0 & 122 & 5221 & 1832 & 1220.731 \\
\cline { 2 - 6 } & Group 1 & 0 & 6489 & 1451 & 1246.203 \\
\cline { 2 - 6 } & Group 2 & 0 & 3219 & 1315 & 812.8781 \\
\hline \multirow{2}{*}{$\begin{array}{l}\text { FLP - real } \\
\text { distances }\end{array}$} & Group 0 & 43 & 4836 & 1330 & 1051.289 \\
\cline { 2 - 6 } & Group 1 & 0 & 5432 & 1049 & 1006.182 \\
\cline { 2 - 6 } & Group 2 & 0 & 2797 & 518 & 629.064 \\
\hline \multirow{2}{*}{$\begin{array}{l}\text { FLP weighted } \\
\text { distances }\end{array}$} & Group 0 & 197 & 3770 & 1998 & 1091.904 \\
\cline { 2 - 6 } & Group 1 & 0 & 2291 & 893 & 573.3682 \\
\cline { 2 - 6 } & Group 2 & 0 & 1748 & 564 & 422.3245 \\
\hline
\end{tabular}

To support our argument about Rawlzian difference principle modeling as a weighed version of FLP formulation, we compare the different metrics for the least well-off group on Fig. 2. Although minimum and mean distances of the regular FLP (considered a utilitarian approach) benefits group 0 compared to the weighed FLP, max distance is greatly reduced. This indicator is important because it represents the outliers that live far away from the desired service. Sustained by a low standard deviation, meaning that the distance is evenly distributed among group 0 , applying a cost factor to the distance tends to create a more suitable scenario for lower socio-economic groups.

\section{Summary and Outlook}

In this work we discussed how justice principles can relate to spatial justice and proposed two models based on facility location problem optimization. The first model was a capacitated facility location that aimed to minimize the sum of the distances pondered by the location demand. By doing that, we aimed to create a scenario that maximizes the overall welfare as the opportunities tend to be close to denser areas. The second model is our proposal for a Rawl's difference principle. It is a variation of the first one, 


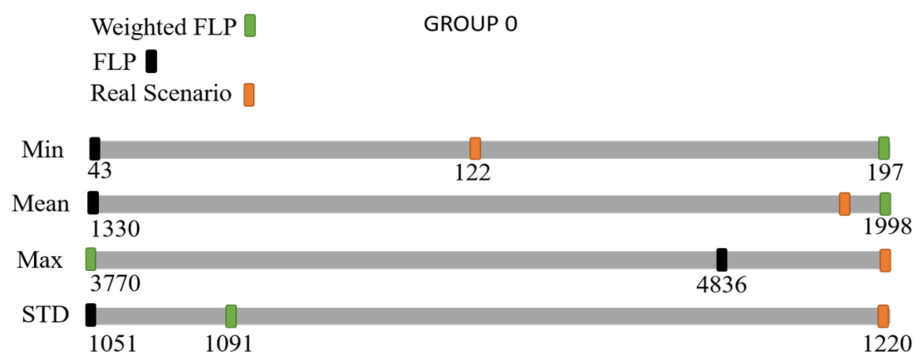

Fig. 2. Accessibility metrics comparison for Group 0 (least well-off).

weighting the distance by an exponential cost function, or "social cost", that will force the optimization to favor lesser well-off regions.

The results have shown that the occupation pattern and, therefore, the spatial context of analyzed area, plays an important role in opportunity location. The fact that the most well-off group was also benefited when our cost function was deliberately chosen to favor the least well-off, does not imply that Rawlzian model will improve overall wellbeing. It seems that spatial distribution of social groups displays complex dynamics during the optimization. This behavior is directly related to the $B$ chosen in the exponential factor, as the cost of denser and mixed areas on urban centers can get not that different, leaving the cost function effectiveness to outliers. An experimental approach to tune the $B$ to impact relevant distances can be done, similar as conducted by [22]. But the relevant distances and affected groups can be context dependent.

The weighed FLP model was able to turn the configuration in favor of the least welloff group, even though not by all accessibility metrics. By greatly reducing the maximum distance, this group tend to stay closer to desired opportunities. In future works, the standard deviation can be also optimized to create even distribution of services. Also, the fact that our utilitarianism model (FLP) created more even opportunity distribution than the Rawlsian exemplifies that fair and justice can be achieved by different perspectives.

This discussion illustrates how spatial justice modeling is not a trivial task. Nevertheless, we argue that "social cost" functions can act as a proxy to understand the relation between relevant opportunities and the socio-economic distribution in a given territory. By weighting distances with social cost function, it can be possible to propose a support decision system to make interventions on the desired services configuration. For instance, it can be possible to suggest a new location for a service that minimizes the overall mean distance by the two different justice perspectives, in a similar way that Fig. 2 illustrates.

\section{References}

1. Hall, P.: Cities of Tomorrow: An Intellectual History of Urban Planning and Design Since 1880 (2014)

2. Porter, M.E.: Clusters and the new economics of competition. Harv. Bus. Rev. 76, 77-90 (1998)

3. Marques, J., Wolf, J., Feitosa, F.: Accessibility to primary schools in Portugal: a case of spatial inequity? Reg. Sci. Policy Pract. n/a (2020). https://doi.org/10.1111/rsp3.12303 
4. De Toni, A., Di Martino, P., Dax, T.: Location matters. Are science and policy arenas facing the Inner Peripheries challenges in EU? Land Use Policy 100, 105111 (2021). https://doi.org/ 10.1016/j.landusepol.2020.105111

5. Scandurra, R., Cefalo, R., Kazepov, Y.: Drivers of youth labour market integration across European regions. Soc. Indic. Res. 154(3), 835-856 (2021). https://doi.org/10.1007/s11205020-02549-8

6. Copus, A., Mantino, F., Noguera, J.: Inner peripheries: an oxymoron or a real challenge for territorial cohesion? Ital. J. Plan. Pract. 7, 24-49 (2017)

7. Stiglitz, J.: The price of inequality. New Perspect. Q. 30, 52-53 (2013). https://doi.org/10. 1111/npqu. 11358

8. Wolf, J., Feitosa, F., Marques, J.L.: Efficiency and equity in the spatial planning of primary schools. Int. J. E-Planning Res. 10, 21-38 (2021). https://doi.org/10.4018/IJEPR.2021010102

9. Drezner, Z., Hamacher, H.W.: Facility Location: Applications and Theory. Springer, Heidelberg (2002)

10. Pereira, R.H.M., Schwanen, T., Banister, D.: Distributive justice and equity in transportation. Transp. Rev. 37, 170-191 (2017). https://doi.org/10.1080/01441647.2016.1257660

11. Klose, A., Drexl, A.: Facility location models for distribution system design. Eur. J. Oper. Res. 162, 4-29 (2005)

12. Mandal, J., Ponnambath, D.K., Parija, S.C.: Utilitarian and deontological ethics in medicine. Trop. Parasitol. 6, 5-7 (2016). https://doi.org/10.4103/2229-5070.175024

13. Kymlicka, W.: Contemporary Political Philosophy: An Introduction. Oxford University Press, Oxford (2002)

14. Fainstein, S.S.: Spatial justice and planning. In: Readings in Planning Theory: Fourth Edition, pp. 258-272. Wiley, Chichester (2016)

15. Sen, A.: Inequality Reexamined. Harvard University Press, New York (1992)

16. Rawls, J.: A Theory of Justice. Harvard University Press, Cambridge (1971)

17. Rawls, J.: The Basic Liberties and Their Priority. University of Utah Press, Salt Lake City (1981)

18. Tsou, K.W., Hung, Y.T., Chang, Y.L.: An accessibility-based integrated measure of relative spatial equity in urban public facilities. Cities 22, 424-435 (2005). https://doi.org/10.1016/j. cities.2005.07.004

19. Taleai, M., Sliuzas, R., Flacke, J.: An integrated framework to evaluate the equity of urban public facilities using spatial multi-criteria analysis. Cities 40, 56-69 (2014). https://doi.org/ 10.1016/j.cities.2014.04.006

20. Talen, E.: The social equity of urban service distribution: an exploration of park access in Pueblo, Colorado, and Macon, Georgia. Urban Geogr. 18, 521-541 (1997). https://doi.org/ 10.2747/0272-3638.18.6.521

21. Lee, J., Lubienski, C.: The impact of school closures on equity of access in Chicago. Educ. Urban Soc. 49, 53-80 (2017). https://doi.org/10.1177/0013124516630601

22. Vale, D.S., Saraiva, M., Pereira, M.: Active accessibility: a review of operational measures of walking and cycling accessibility. J. Transp. Land Use 9, 209-235 (2016)

23. Sen, A.: Human rights and capabilities. J. Hum. Dev. 6, 151-166 (2005). https://doi.org/10. 1080/14649880500120491

24. Raghavan, S., Sahin, M., Salman, F.S.: The capacitated mobile facility location problem. Eur. J. Oper. Res. 277, 507-520 (2019). https://doi.org/10.1016/j.ejor.2019.02.055

25. Farahani, R.Z., Asgari, N., Heidari, N., et al.: Covering problems in facility location: a review. Comput. Ind. Eng. 62, 368-407 (2012)

26. Hooker, J.N.: Optimality conditions for distributive justice. Int. Trans. Oper. Res. 17, 485-505 (2010). https://doi.org/10.1111/j.1475-3995.2009.00742.x 
27. Vale, D.S., Pereira, M.: The influence of the impedance function on gravity-based pedestrian accessibility measures: a comparative analysis. Environ. Plan. B Urban Anal. City Sci. 44, 740-763 (2017). https://doi.org/10.1177/0265813516641685

Open Access This chapter is licensed under the terms of the Creative Commons Attribution 4.0 International License (http://creativecommons.org/licenses/by/4.0/), which permits use, sharing, adaptation, distribution and reproduction in any medium or format, as long as you give appropriate credit to the original author(s) and the source, provide a link to the Creative Commons license and indicate if changes were made.

The images or other third party material in this chapter are included in the chapter's Creative Commons license, unless indicated otherwise in a credit line to the material. If material is not included in the chapter's Creative Commons license and your intended use is not permitted by statutory regulation or exceeds the permitted use, you will need to obtain permission directly from the copyright holder.

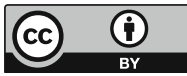

